\title{
A Case of Crizotinib-Resistant Lung Adenocarcinoma Harboring a KRAS Mutation and an EML4-ALK Fusion Gene
}

\author{
Satoshi Anai ${ }^{a}$, d, Kunihiro Suzukia ${ }^{\text {, }}$ Kayo Ijichia, b, Taishi Harada ${ }^{\text {a }}$, Gouji Toyokawa ${ }^{c}$, Takashi Seto ${ }^{c}$, \\ Mitsuhiro Takenoyama ${ }^{\mathrm{c}}$, Koichi Takayama ${ }^{\mathrm{a}}$, Yukito Ichinose ${ }^{\mathrm{c}}$, Yoichi Nakanishi ${ }^{\mathrm{a}}$
}

\begin{abstract}
Here, we report a case of lung adenocarcinoma resistant to crizotinib harboring KRAS mutation and the echinoderm microtubule-associated protein-like 4 (EML4)-anaplastic lymphoma kinase $(A L K)$ fusion gene. Our case suggests that KRAS mutation in addition to EML4$A L K$ fusion gene may cause the resistance to crizotinib.
\end{abstract}

Keywords: $E M L 4-A L K$ fusion gene; $K R A S$ gene mutation; Crizotinib

\section{Introduction}

The echinoderm microtubule-associated protein-like 4 $(E M L 4)$-anaplastic lymphoma kinase $(A L K)$ fusion gene in lung cancer is mutually exclusive with epidermal growth factor receptor (EGFR) and $K R A S$ mutations. If $E G F R$ or $K R A S$ gene mutations have been detected, it is unlikely that $E M L 4-$ $A L K$ fusion gene will be present in the same patient. Here, we describe a case of lung adenocarcinoma resistant to crizotinib harboring KRAS mutation and the EML4-ALK fusion gene.

\section{Case Report}

A 54-year-old female non-smoker underwent right middle and lower lobectomy for stage IIIA lung adenocarcinoma in Janu-

\section{Manuscript accepted for publication November 13, 2014}

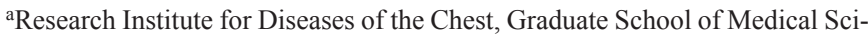
ences, Kyushu University, Fukuoka, Japan

${ }^{b}$ Division of Pathophysiological and Experimental Pathology, Department of Pathology, Kyushu University, Fukuoka, Japan

'Department of Thoracic Oncology and Clinical Research Institute, National Kyushu Cancer Center, Fukuoka, Japan

${ }^{\mathrm{d}}$ Corresponding Author: Satoshi Anai, Research Institute for Diseases of the Chest, Graduate School of Medical Sciences, Kyushu University, 3-1-1 Maidashi, Higashi-ku, Fukuoka 812-8582, Japan.

Email: anai-s@kokyu.med.kyushu-u.ac.jp

doi: http://dx.doi.org/10.14740/jmc1985w ary 2006 (Fig. 1A). The pathological diagnosis was invasive mucinous adenocarcinoma (Fig. 1B), and the patient received four cycles of platinum-based adjuvant chemotherapy. Peptide nucleic acid-locked nucleic acid polymerase chain reaction clamp method performed on formalin-fixed paraffin-embedded (FFPE) resected tumor tissue showed that the sample was negative for epidermal growth factor receptor (EGFR) gene mutation. However, the mutant $K R A S$ codon 12 (c. $35 \mathrm{G}>\mathrm{A}$, p.Gly12Asp) was identified using direct sequencing (Fig. 2) of tissue from the same tissue block.

The patient relapsed in January 2007, presenting with multiple lung metastases, and was treated with gefitinib, docetaxel, erlotinib, S-1 and pemetrexed. Among these chemotherapies, she responded to S-1 for 6 months and to pemetrexed for 18 months. The patient requested crizotinib treatment, and we therefore assessed the presence of the EML4-ALK fusion gene using the same FFPE tissue block. Fluorescence in situ hybridization (FISH) for $A L K$ rearrangements and immunohistochemistry (IHC) for $A L K$ expression were both negative, but reverse transcription-polymerase chain reaction (RT-PCR) and sequencing identified variant 1 of the EML4-ALK fusion gene (Fig. 2). The patient received crizotinib treatment, but her disease was found to have progressed after 42 days of therapy (Fig. 3).

\section{Discussion}

EML4-ALK gene translocation was initially reported in 2007 [1]. $A L K$-positive lung cancers account for roughly $2-5 \%$ of all non-small-cell lung cancer cases [1]. The frequency of EML4$A L K$ translocation variant 1 is approximately $30 \%$ [1]. Comparison of FISH, IHC, and RT-PCR methodologies for detecting EML4-ALK translocation variant 1 showed RT-PCR to be the most sensitive [2], as in the current case. The presence of the $E M L 4-A L K$ fusion gene in lung cancer is mutually exclusive with $E G F R$ and $K R A S$ mutations [1], and patients with $E G F R$ or KRAS gene mutations are unlikely to also harbor the $E M L 4-A L K$ fusion gene. However, some patients with lung adenocarcinoma with both the KRAS mutation and EML4-ALK fusion gene were reported by Martelli et al [3] and Doebele et al [4].

Although the PROFILE 1007 study reported higher response rates $(65 \%)$ to crizotinib than to standard chemothera- 


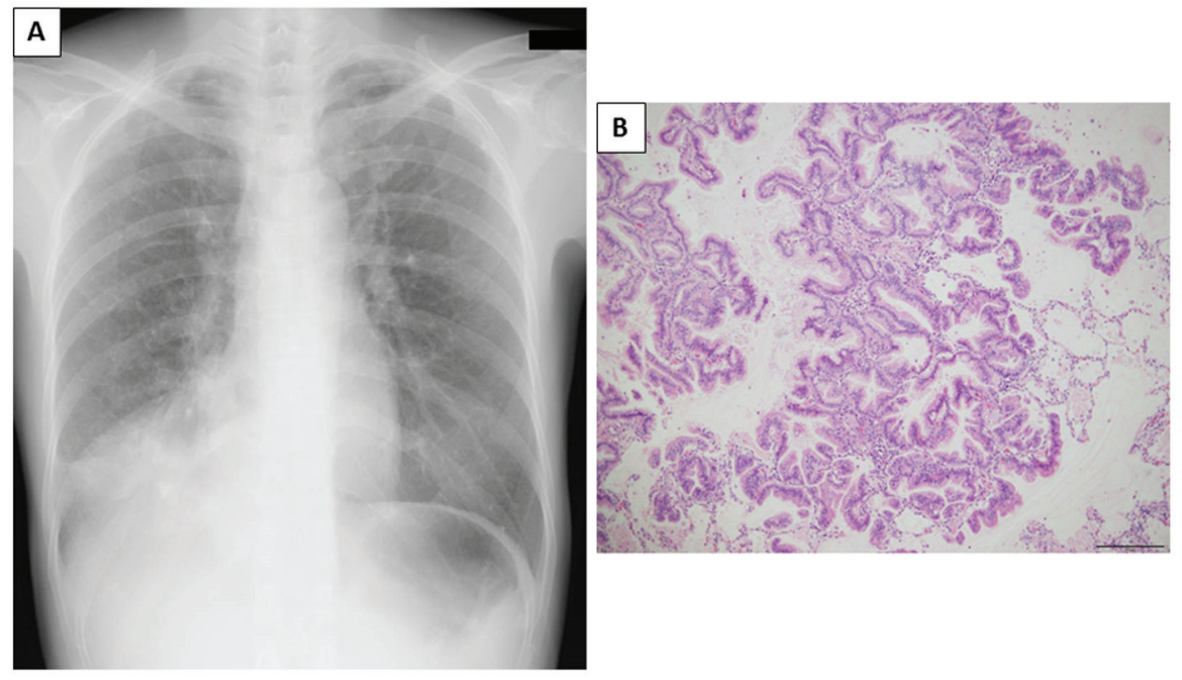

Figure 1. Chest radiography revealed a mass shadow in the right lower lung field (A). Histology of the primary tumor showed an invasive mucinous adenocarcinoma (hematoxylin and eosin stain, $\times 100$ magnification, internal scale bar $=200 \mu \mathrm{m})(B)$.

py in patients with $A L K$-positive lung cancer who had received one prior platinum-based regimen [5], the current case was intrinsically refractory to crizotinib. It has been suggested that, in cases with concomitant presence of the EML4-ALK fusion gene and the KRAS mutation prior to crizotinib administration, the KRAS mutation might serve as a driver of crizotinib resistance [4], and cytotoxic chemotherapies may be more effective in such cases [4]. Indeed, the current patient experienced longer progression-free survival times with chemotherapies such as S-1 and pemetrexed, compared with crizotinib. This study suggests that the detection of a single driver gene mu-

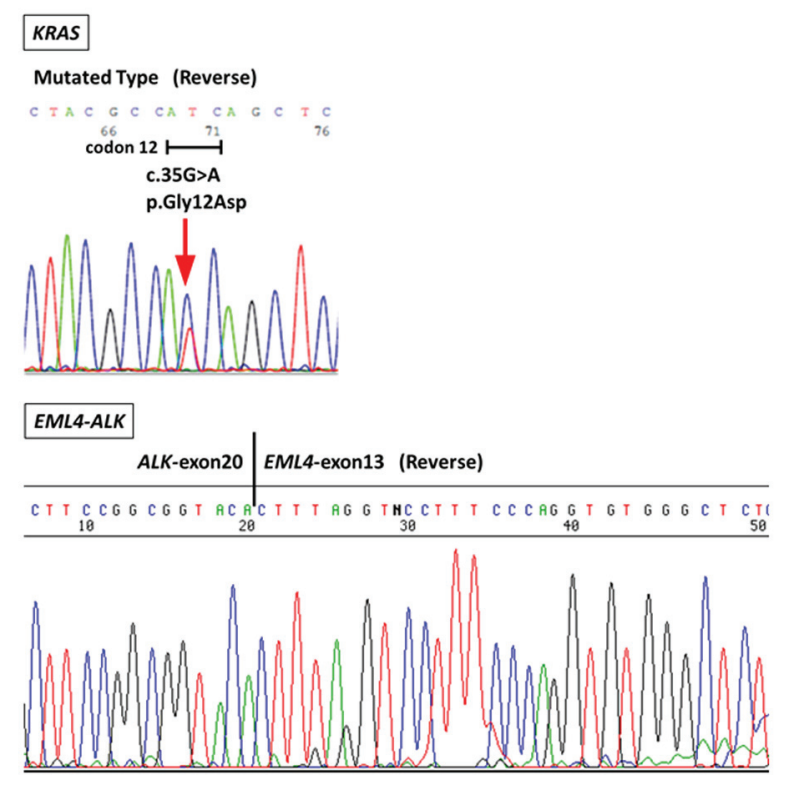

Figure 2. KRAS mutation of codon 12 was positive. Variant 1 of the EML4-ALK translocation was identified by RT-PCR and sequencing assays. tation is inadequate for patient selection, and comprehensive examination of driver gene mutations may be needed to allow personalized cancer treatment.

\section{Sources of Support}

The authors report no sources of funding for this work.

\section{Conflict of Interest}

The authors have declared no conflicts of interest.

\section{References}

1. Mitsudomi T, Yatabe Y, Akita H, Genma A, Soda M, Toyooka S, Nakagawa K, et al. Guidance for ALK Gene Testing in Lung Cancer Patients, Version 1.2. Biomarker Committee, the Japan Lung Cancer Society.

2. Wallander ML, Geiersbach KB, Tripp SR, Layfield LJ. Comparison of reverse transcription-polymerase chain reaction, immunohistochemistry, and fluorescence in situ hybridization methodologies for detection of echinoderm microtubule-associated proteinlike 4-anaplastic lymphoma kinase fusion-positive non-small cell lung carcinoma: implications for optimal clinical testing. Arch Pathol Lab Med. 2012;136(7):796-803.

3. Martelli MP, Sozzi G, Hernandez L, Pettirossi V, Navarro A, Conte D, Gasparini P, et al. EML4-ALK rearrangement in non-small cell lung cancer and non-tumor lung tissues. Am J Pathol. 2009;174(2):661-670.

4. Doebele RC, Pilling AB, Aisner DL, Kutateladze TG, Le AT, Weickhardt AJ, Kondo KL, et al. Mechanisms of resistance to crizotinib in patients with ALK gene rear- 


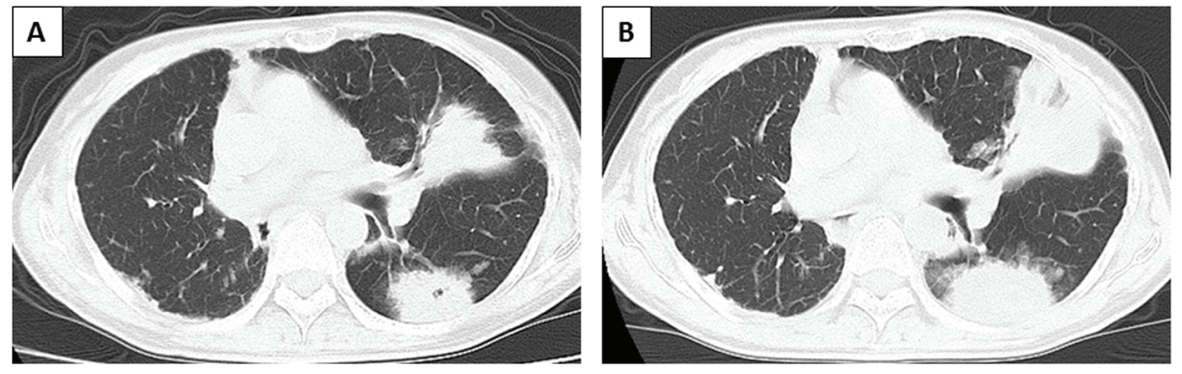

Figure 3. Comparison of computed tomography scans of the thorax before crizotinib (A), and 42 days after crizotinib treatment (B) showed tumor enlargement.

ranged non-small cell lung cancer. Clin Cancer Res. 2012;18(5):1472-1482.

5. Shaw AT, Kim DW, Nakagawa K, Seto T, Crino L, Ahn
MJ, De Pas T, et al. Crizotinib versus chemotherapy in advanced ALK-positive lung cancer. N Engl J Med. 2013;368(25):2385-2394. 